\title{
TRAJETÓRIA DA PROTEÇÃO SOCIAL BRASILEIRA À INFÂNCIA E À ADOLESCÊNCIA NOS MARCOS DAS RELAÇÕES SOCIAIS CAPITALISTAS
}

\author{
TRAJECTORY OF SOCIAL PROTECTION TO BRAZILIAN CHILDHOOD AND \\ ADOLESCENCE IN THE MARK OF THE CAPITALIST SOCIAL RELATIONS
}

Juliana Iglesias Melim ${ }^{1}$

\begin{abstract}
RESUMO
O presente artigo é fruto das reflexões e análises iniciadas a partir do desenvolvimento das atividades de pesquisa e extensão do Núcleo de Estudos da Criança e do Adolescente (NECA) da Universidade Federal do Espírito Santo. Nesse contexto, as linhas que se seguem procuram expressar os debates realizados, bem como as análises construídas a partir da leitura crítica da realidade, especialmente no que se refere à trajetória da proteção social brasileira voltada para as crianças e adolescentes, à conquista do marco regulatório - Estatuto da Criança e do Adolescente - e aos principais desafios que se apresentam para a consolidação dos direitos na ordem burguesa.
\end{abstract}

PALAVRAS-CHAVE: Desigualdade Social. Proteção Social. Direitos. Criança e Adolescente.

\section{ABSTRACT}

This article is the result of reflection and analysis started from the development of research and extension activities of the Center for Studies of Children and Adolescents - Federal University of Espírito Santo. In this context, the lines that follow seek to express the discussions, as well as analyzes built on the critical reading of reality, especially with regard to the trajectory of the Brazilian social protection aimed at children and adolescents, the conquest of the regulatory framework - Statute of Children and Adolescents - and the main challenges facing the consolidation of rights in the bourgeois order.

KEYWORDS: Social Inequality. Social Protection. Rights. Children and Adolescents.

\section{TRAJETÓRIA DA PROTEÇÃO SOCIAL BRASILEIRA À INFÂNCIA E À ADOLESCÊNCIA}

O reconhecimento de uma política pública direcionada para o atendimento da infância e adolescência no Brasil somente foi possível com a aprovação do Estatuto da Criança e do Adolescente (ECA) em 1990, pois é a partir daí que se instaura e se desdobra o reconhecimento constitucional de criança/adolescente como sujeitos de

\footnotetext{
${ }^{1}$ Assistente Social, docente do curso de Serviço Social na Universidade Federal do Esp rito Santo, Coordenadora do Núcleo de Estudos da Criança e do Adolescente (NECA/UFES), Conselheira do Conselho Federal de Serviço Social na gest o 2011-2014. Telefone 5527 99893-4786. E-mail: juliana_melim@ahoo.com.r.

Serv. Soc.\& Saúde, Campinas, SP v. 11, n. 2 (14) p. 167-184 jul./ dez. 2012 ISSN 1676-6806
} 
direito em situação peculiar de desenvolvimento e da adoção da proteção integral. A Doutrina da Proteção Integral, inaugurada pelo Estatuto, afirma o valor da criança e do adolescente como seres humanos; a necessidade de especial respeito à sua condição de pessoa em desenvolvimento; o valor prospectivo da infância e da juventude, como portadoras da continuidade do seu povo, da sua família e da espécie humana e o reconhecimento de sua vulnerabilidade, o que torna as crianças e os adolescentes merecedores de proteção integral por parte da família, da sociedade e do Estado, o qual deverá atuar através de políticas específicas para o atendimento, a promoção e a defesa de seus direitos (COSTA, 1993). De fato, antes disso os direitos não fizeram parte da história da infância/adolescência, cujas práticas sociais no Brasil voltadas aos estratos empobrecidos da classe trabalhadora têm marcas assistencialistas, corretivas e repressoras.

Quando analisamos a história das concepções e práticas relativas às crianças e adolescentes em nosso país, é possível identificar que o modo pelo qual a sociedade percebeu esses sujeitos direcionou uma série de ações voltadas para o atendimento àquelas parcelas da população.

Os estudos realizados apontam um predomínio de ações voltadas especialmente para as crianças pobres, abandonadas e delinquentes, então denominadas "menores". A ideia de criminalização da pobreza reforçou, historicamente, a implementação dessas ações, na tentativa de evitar que aquelas crianças se tornassem potenciais marginais no futuro e ameaçassem a ordem social instaurada. Podemos afirmar que a concepção de criança e adolescente tidos como "menores" promoveu uma triste história de práticas violentas e repressoras que não garantiram a cidadania desses sujeitos.

Uma revisão da história da assistência à infância no Brasil, desde o período colonial, mostra-nos que toda prática assistencial voltada para crianças pobres se pautava no trabalho. As crianças índias eram catequizadas enquanto aprendiam a trabalhar; os pequenos escravos, desde muito cedo, passavam a servir aos seus senhores; as crianças abandonadas recebiam "proteção" das Santas Casas de Misericórdia até os sete anos de idade e depois eram entregues para o trabalho; as crianças órfãs eram destinadas aos asilos, onde aprendiam a desenvolver o "sentimento de amor ao trabalho" (RIZZINI; PILOTTI, 1995).

Deve-se ressaltar que, aqui no Brasil, mesmo em se tratando de uma industrialização tardia, a criança passou a ser vista como futura mão-de-obra para a Serv. Soc.\& Saúde, Campinas, SP v. 11, n. 2 (14) p. 167-184 jul./ dez. 2012 ISSN 16766806 
indústria, e a capacidade de trabalho se apresentou, de acordo com a ideologia dominante, como o único bem da população empobrecida. Por isso, a centralidade do trabalho nas ações de assistência para os pobres continuará ainda no período republicano. Era preciso incutir a disciplina do trabalho nas crianças, objetivando a "proteção da sociedade" contra "futuros" delinquentes ociosos.

Também se mantiveram a aplicação de castigos violentos e as péssimas condições de vida em que as crianças eram submetidas. Exemplos dessa situação não faltam na história brasileira de "atenção" à criança e ao adolescente. A resistência à catequese era capitulada na lei portuguesa como motivo suficiente para o uso da força; as crianças escravas, além de submetidas a frequentes castigos, morriam com facilidade, devido às precárias condições em que viviam seus pais; nas Rodas dos Expostos, a mortalidade era elevada em função da falta de condições adequadas de higiene, alimentação e cuidados em geral (RIZZINI; PILOTTI, 1995).

A reclusão também será uma constante característica das ações voltadas para as crianças e adolescentes brasileiros. Os asilos, bem como as demais instituições de internação que existiam - Colônias Correcionais, Patronatos Agrícolas, Institutos Públicos -, conforme relata Rizzini (1997), eram casas situadas longe das cidades, inclusive em ilhas, nas quais se colocavam dezenas de crianças de 7 a 8 anos que passavam a ser educadas numa instrução quase que exclusivamente religiosa, vivendo sem higiene e, muitas vezes, em ambientes escuros e sem ventilação. Essas crianças eram pessimamente alimentadas, sujeitas a castigos severos, dos quais o mais suave era o suplício da fome e da sede. O trabalho era tido como a forma de se evitar que os asilos se tornassem viveiros de parasitas.

$\mathrm{O}$ isolamento dos desajustados em espaços educativos e corretivos constituía estratégia segura para a manutenção 'pacífica' da parte sadia da sociedade. O propósito de classificar os diferentes e confinálos em espaços de segregação e de isolamento afinava com a modernidade do país, que renegava seu passado escravista e trilhava o caminho da civilização pela negação permanente da barbárie que se apresentava sob a forma de diversidade irresponsável e caótica. Tratava-se, antes de tudo, de conferir ordem a uma população multifacetada e disforme (ADORNO, 1990, p. 9).

É nesse contexto que surgem as polícias das famílias, com o discurso de que existiam para o bem dos infantes. Essas polícias tinham o poder de entrar nas casas e intervir na moralidade da família. A pobreza ou a orfandade justificava a retirada da criança do seu lar e de sua comunidade (RIZZINI; PILLOTI, 1995). A história do Serv. Soc.\& Saúde, Campinas, SP v. 11, n. 2 (14) p. 167-184 jul./ dez. 2012 ISSN 16766806 
controle social formal da infância como estratégia específica constitui um exemplo paradigmático de construção de uma categoria de indivíduos para quem a proteção, muito mais que constituir um direito, consiste numa imposição. Uma proteção que será concebida apenas na medida das distintas variações da segregação, que, na melhor das hipóteses, reconhece a criança como objeto de compaixão, mas nunca como sujeito detentor de direitos.

Essas práticas se perpetuaram até que, em 1927, criou-se uma legislação específica para a infância brasileira - o Código de Menores Mello Mattos. Pela primeira vez, foram criadas, em forma de lei, diretrizes para o "cuidado" com a infância empobrecida. Entretanto, essas diretrizes eram apenas relacionadas ao internamento das crianças, reforçando as práticas anteriores (RIZZINI; PILLOTI, 1995).

Com o Código, ganhava ênfase a figura do Juiz de Menores, que tinha como atribuições julgar, administrar e buscar soluções socioassistenciais. Também aparece a figura do Comissário de Menores, que era uma espécie de polícia para os adolescentes. Eles procuravam os infratores, não para solucionar ou prevenir infrações cometidas, mas para retirá-los do convívio social (RIZZINI; PILLOTI, 1995). "Uma imagem de medo [por parte da "sociedade"] que se espelhava em verdadeira caçada aos ‘comportamentos periféricos' objeto de intimidação policial, de sanção judiciária, de ação filantrópica" (ADORNO, 1990, p. 9).

Somente nos anos 40 o governo inaugura uma política mais nítida de atendimento à infância pobre, criando órgãos federais responsáveis por planejar e gerir as ações para essa parcela da população. A política para a infância passou a ser centralizada na esfera federal de governo. Surge, nesse período, o Serviço de Atendimento ao Menor (SAM), que passa a ser responsável pela orientação e sistematização dos serviços assistenciais realizados nos patronatos agrícolas e nos institutos públicos. O SAM encaminhava os menores, após uma triagem, para esses espaços de internamento.

As instituições oficiais e particulares que atendiam os "menores" enviados pelo SAM mantiveram as experiências mais condenadas na assistência a crianças e adolescentes. A vigilância e os castigos corporais eram práticas comuns nas instituições. A prática da vigilância determina que todos façam o que foi claramente indicado como exigido, sob condições em que a infração de uma pessoa chega a salientar-se diante da obediência visível dos internos com os funcionários das instituições. A vigilância Serv. Soc.\& Saúde, Campinas, SP v. 11, n. 2 (14) p. 167-184 jul./ dez. 2012 ISSN 16766806 
também quer dizer que os internados dessas instituições têm todo o dia determinado, o que, para eles, equivale a dizer que todas as suas necessidades essenciais precisam ser planejadas. Nessas instituições, a autonomia e a individualidade dos sujeitos eram, a todo o momento, negadas. Os padrões do vestuário, das rotinas e das atividades realizadas reforçavam essa ideia. Já no que diz respeito às práticas de violência, era comum uma série de rebaixamentos, degradações e humilhações. A violência física era tamanha, que chegava a assumir proporções de escândalo público, dada a extrema violência de surras que levavam os internos à morte. Os maus tratos ainda se davam através da péssima qualidade da alimentação, da superlotação, da falta de higiene, da precariedade das instituições e da exploração sexual (RIZZINI; PILLOTI, 1995).

Além da violência, também foram comuns nessa instituição denúncias de corrupção, que envolviam seus funcionários. A corrupção atingia o serviço em todos os níveis, desde o Ministério da Justiça até as instituições de atendimento.

Após tentativas de reformar o Serviço, o projeto de um novo órgão - o Instituto Nacional de Assistência a Menores (INAM) - foi apresentado pelo Presidente da República ao Congresso Nacional em 1955. O Projeto pedia a extinção da figura do Diretor do SAM e a criação de uma diretoria e um conselho, sendo este último formado por representantes da comunidade. Quanto aos objetivos e à estruturação do Instituto, não se diferenciava dos do SAM. Havia somente a preocupação em delinear com clareza suas finalidades e dar-lhe maior autonomia, pois o Serviço era subordinado ao Departamento Administrativo do Ministério da Justiça, não tendo autonomia sobre as questões de infraestrutura do órgão, tais como: material, pessoal, obras, contratos, pagamentos e prestações de contas.

Após a entrega ao Congresso do Anteprojeto de Lei que transformaria o Serviço de Assistência a Menores (SAM) em Instituto Nacional de Assistência a Menores (INAM), foi instaurada uma Comissão Parlamentar de Inquérito para apurar irregularidades ocorridas no SAM. No entanto, essa CPI não apresentou resultado que ameaçasse a existência do Serviço. Não obstante, seis anos depois, com a realização de uma sindicância para novamente apurar as irregularidades no SAM, foi proposta sua extinção, sendo para isso nomeada uma comissão para elaborar o anteprojeto de criação da Fundação Nacional de Bem-Estar do Menor (FUNABEM) e as Fundações Estaduais de Bem-Estar do Menor (FEBEMs), anteprojeto esse aprovado em $1^{\circ}$ de dezembro de 1964 e transformado na lei n. ${ }^{\circ} 4.513$ (RIZZINI; PILLOTTI, 1995). 
Mudavam-se os nomes, mas as práticas e as representações continuavam as mesmas: as crianças e adolescentes pobres ainda eram os "menores" da sociedade e, por isso, a violência praticada contra eles era aceita por muitos segmentos sociais.

O sistema FUNABEM/ FEBEMs tinha como meta oficial proteger a criança/adolescente dos "desajustamentos" sociais e da marginalização, visando integrála e ressocializá-la na vida em comunidade. A função da Fundação era:

Art. 5. Formular e implantar a Política Nacional do Bem-Estar do Menor, mediante o estudo do problema e planejamento das soluções, a orientação, coordenação e fiscalização das entidades que executem essa política (Lei 4.513 apud RIZZINI; PILOTTI, 1995, p. 300).

As práticas internas da instituição reproduziam a lógica do regime militar vigente na época: repressão, confinamento e violência. Assim, a internação mostrou-se mais uma vez como um sistema degradante e que agravou a situação de milhares de crianças/adolescentes brasileiros, produzindo e reproduzindo entre eles a marginalidade. A questão da assistência à infância passou, com tantas outras coisas, para a esfera de competência do governo militar. Este via na questão social e, no interior desta, na questão do "menor", um problema de segurança nacional, julgando-o, portanto, objeto legítimo de sua intervenção e normalização. As intervenções se apoiavam no discurso da "prevenção da marginalização do menor" (RIZZINI; PILOTTI, 1995), reforçando, novamente, a criminalização da pobreza, tão presente na trajetória das ações de combate à pobreza no mundo ocidental.

Com a extinção do SAM, a Fundação Nacional de Bem-Estar do Menor apresentou-se como sua antítese, isto é, como uma instituição autônoma, administrativa e economicamente, e que afastava o fantasma da burocracia e da corrupção que tinha caracterizado o SAM.

A FUNABEM era o órgão central, de caráter normativo e encarregado de repassar recursos. E, para que houvesse este repasse, era necessária a criação de organismos locais. Desse modo, foram criadas, nos estados brasileiros, as Fundações Estaduais do Bem-Estar do Menor - FEBEMs.

Entretanto, a proposta da FUNABEM, de atendimento à criança e ao adolescente considerados menores, através de campanhas preventivas e descentralização de suas atividades, não obteve bons resultados. Pelo contrário: era crescente o número de internações. Diante desse quadro, foi instaurada uma Comissão Parlamentar de Inquérito, que ficou conhecida como a CPI do Menor. A CPI funcionou como um Serv. Soc.\& Saúde, Campinas, SP v. 11, n. 2 (14) p. 167-184 jul./ dez. 2012 ISSN 16766806 
laboratório de pesquisas e busca de soluções para os problemas relacionados ao “menor" (RIZZINI; PILOTTI, 1995).

A CPI apresentou, em 1976, um diagnóstico revelando que havia no Brasil cerca de 25 milhões de "menores" carentes e/ou abandonados, ou seja, 1/3 da população infanto-juvenil. A crescente urbanização e migração e, consequentemente, o incremento populacional contribuíram para o aparecimento, ao redor das cidades, dos "cinturões de pobreza". Diante desse quadro, cabia ao órgão competente - neste caso, a FUNABEM a implementação do Plano Nacional de Bem-Estar do Menor. No entanto, até aquele momento, a Fundação não apresentava condições para solucionar essa questão, que encontrava as suas raízes na péssima distribuição da riqueza produzida socialmente. $\mathrm{O}$ relatório ainda constatou que as FEBEMs também não dispunham de recursos suficientes para enfrentar a questão, o que confirma o caráter de descaso que foi dado às políticas sociais brasileiras (RIZZINI; PILOTTI,1995).

Ao final da CPI, foi apresentada ao Presidente da República a recomendação para a criação do Sistema de Proteção do Menor, implicando na criação de um Ministério Extraordinário coordenando os demais órgãos envolvidos, e que teria apoio financeiro de um Fundo Nacional de Proteção do Menor, com autonomia administrativa e financeira e cuja função seria mobilizar a comunidade em relação ao assunto. Estimulava-se, assim, uma ação integrada entre governo-empresa-comunidade no sentido de promover "o recolhimento dos menores abandonados que perambulam pelas ruas das nossas principais cidades - principalmente nas regiões metropolitanas, densas de marginalização social" (RIZZINI; PILOTTI, 1995, p. 315).

No entanto, esse projeto não foi concretizado. A FUNABEM permaneceu no atendimento à "questão do menor" e, após a reforma ocorrida em 1974, a Fundação passou a ser subordinada ao Ministério da Previdência e Assistência Social (MPAS).

Dessa forma, podemos pontuar algumas características que marcaram a história das políticas sociais brasileiras relativas à infância e à adolescência, em que predominava como produção simbólica a respeito dos indivíduos dessas faixas etárias a concepção segundo a qual se tratava de delinquentes e abandonados. Destaca-se a criminalização da pobreza - a criança pobre era tida como um futuro marginal em potencial e, por isso, era preciso reprimi-la e corrigi-la pela violência. As práticas de internação eram priorizadas e a força de trabalho era tida como único bem que a criança pobre possuía. Logo, nessas instituições, crianças e adolescentes eram submetidos ao 
trabalho forçado. As ações foram, historicamente, marcadas pela ênfase na esfera privada e no recuo das funções públicas do Estado. Quando este passa a ter um papel mais marcante nessa área, reforça as ações compensatórias e não-preventivas, centralizando a formulação das políticas na esfera federal de governo. O assistencialismo evidenciava a clara segmentação da população e a não-cidadania das crianças pobres.

Essa situação começa a mudar somente com o processo de derrocada do regime militar, quando, paulatinamente, a infância e adolescência passaram a fazer parte da agenda da luta por direitos na sociedade brasileira.

$\mathrm{O}$ processo de redemocratização da sociedade brasileira levou à instalação da Assembleia Nacional Constituinte e à possibilidade de se estabelecer uma outra ordem social, em novas bases, o que fez com que esses movimentos se articulassem para tentar inscrever na Carta Constitucional direitos sociais que pudessem ser traduzidos em deveres do Estado, através de políticas públicas (CUNHA; CUNHA, 2002, p. 13).

A promulgação da Constituição Federal de 1988, também conhecida como Constituição Cidadã, foi fruto de um contexto de lutas, contradições, reivindicações e mobilizações de diversos segmentos da sociedade, e marcou um novo direcionamento político e social em nosso país, de tal modo que as demandas populares passaram a ter a possibilidade de se manifestar no interior do Estado.

Este período foi marcado pela implementação da Carta Constitucional que normatizou os direitos e deveres da sociedade brasileira. A Constituição de 1988 trouxe vários avanços, pois incluiu a defesa dos direitos das mulheres, índios, negros, crianças e adolescentes, entre outros.

No âmbito da criança e do adolescente, a Constituição, em seu artigo 227, normatizou preceitos que possibilitaram a regulamentação do Estatuto da Criança e do Adolescente ao determinar como dever da família, da sociedade e do Estado a responsabilidade pelo desenvolvimento integral de crianças e adolescentes.

É correto afirmar que, já no início da década de 80, várias mudanças ocorreram nas formas de pensar e atender a infância e a adolescência, o que envolveu movimentos sociais, fóruns, etc. Segundo Doimo (1997, p. 140),

[...] quanto aos direitos civis, destaca-se o Movimento Nacional de Meninos e Meninas de Rua (MNMMR) que, já em seu primeiro encontro, em 1986, congregou 500 meninos de rua de todo país para analisar a conjuntura e declarar as suas necessidades e expectativas, preparando terreno para a elaboração do Estatuto da Criança e do 
Adolescente, a fim de codificar os direitos dos menores [sic] e definir as responsabilidades dos adultos e do Estado.

Também data da década de 80 deu-se a criação do Fórum Nacional Permanente de Entidades Não-Governamentais de Defesa dos Direitos da Criança e do Adolescente - Fórum/DCA.

Outras ações aconteceram no Brasil, seguindo o desejo de mudança na realidade vivenciada pelas crianças e adolescentes. Tivemos os movimentos "Criança e Constituinte", promovido pelo Ministério da Educação, e a campanha "Criança: Prioridade Nacional", que recolheu aproximadamente 250 mil assinaturas de apoio à inclusão de um artigo na Constituição Federal de 1988 que tratasse dos direitos das crianças e adolescente em todo o País. No contexto internacional, destacaram-se, no mesmo período, o Ano Internacional da Criança (1979) e a Convenção dos Direitos das Crianças (1989), marcos importantes para as inovações nos direitos desse segmento.

Assim, a Convenção dos Direitos das Crianças direcionou a elaboração do Estatuto da Criança e do Adolescente, que teve como atores envolvidos: entidades da sociedade civil articuladas no Fórum DCA, dirigentes e técnicos governamentais através do Fórum Nacional de Dirigentes Estaduais de Políticas Públicas para a Criança e o Adolescente (FONACRIAD) e a Frente Parlamentar pelos Direitos da Criança.

\section{ESTATUTO DA CRIANÇA E DO ADOLESCENTE, DESIGUALDADE SOCIAL E POLÍTICA SOCIAL}

Promulgado em 13 de julho de 1990, o Estatuto da Criança e do Adolescente, lei n ${ }^{\circ}$ 8.069, revoga o antigo Código de Menores - que era centrado na repressão e discriminação da infância pobre - e traz inovações, na medida em que introduz a Doutrina da Proteção Integral.

Dessa maneira, o Estatuto mudará a concepção de criança e adolescente que até então permeava sua intervenção nesse campo. A concepção histórica de "menor" abandonado e delinquente é questionada e ele passa a ser considerado sujeito de direitos visto que vive em um Estado Democrático de Direitos -, em condição peculiar de desenvolvimento -, já que ainda está em processo de desenvolvimento físico, mental, moral, espiritual e social -, além de passar a ser encarado como tendo prioridade absoluta. 
Ao revogar o velho paradigma representado pelo Código de Menores, o Estatuto oferece condições legais para que aconteça uma verdadeira mudança, tanto na formulação das políticas sociais para a infância e a juventude como na estrutura de funcionamento dos organismos que atuam nesse campo. De fato, o avanço na legislação direcionará uma nova forma de relação entre o Estado e os usuários das políticas sociais. Com a implantação da nova lei, o padrão de relacionamento deixará de ser vertical, centralizado, manipulador, clientelista e sonegador da criatividade e da iniciativa dos destinatários - padrão que, historicamente, sempre marcou no Brasil a relação entre as classes populares e o ramo social do Estado.

Assim, o Estatuto também introduzirá algumas mudanças no conteúdo, no método e na gestão das ações destinadas à criança e ao adolescente.

No âmbito do conteúdo, as mudanças referem-se ao acréscimo de novos direitos para a infância e a juventude e envolve tanto os direitos individuais (vida, liberdade e dignidade) quanto os coletivos (econômicos, sociais e culturais).

A introdução da Doutrina de Proteção Integral implicará em enormes mudanças na essência da formulação das políticas sociais, que passam a abranger: as políticas sociais básicas, como educação, saúde, habitação, lazer, profissionalização e outras, consideradas direito de todos e dever do Estado; as políticas de assistência social, voltadas para o atendimento compensatório a todos que dela necessitem; as políticas de proteção especial, que envolvem as crianças e adolescentes em situação de risco pessoal e social; e as políticas de garantias, que atendem às crianças e adolescentes envolvidos em conflitos de natureza jurídica. O conjunto articulado dessas ações configura o que denominamos de Sistema de Garantias de Direitos. "Como se vê, os destinatários da nova legislação não são mais apenas 'os menores em situação irregular', mas todas as crianças e adolescentes do Brasil, para os quais o Estatuto tem o valor e o sentido de uma verdadeira Constituição da Infância e da Juventude" (COSTA, 1993, p. 39).

Mudanças de tal amplitude no conteúdo da concepção de criança e adolescente e das políticas sociais correspondentes também vão exigir uma nova visão de métodos, técnicas e organização dos programas de atendimento a essa parcela da população. A mudança de método, segundo Costa (1993, p. 21), “aponta na direção da superação do assistencialismo como princípio definidor das relações entre os pobres e o ramo social do Estado, ou seja, as políticas e programas governamentais voltados para o atendimento de suas necessidades". 
Entende-se que todo trabalho social destinado a essa população deve estar baseado na noção de cidadania e emancipação. Isso significa que a criança e o adolescente não poderão mais ser tratados como objetos passivos da intervenção da família, da sociedade e do Estado. As ações devem ter caráter emancipatório, capaz de transformar as crianças e adolescentes em sujeitos históricos capazes de manejarem seu próprio destino, respeitando suas potencialidades e limitações em cada fase do seu desenvolvimento pessoal e social.

Quanto às mudanças no campo da gestão, o ECA está em consonância com a Constituição Federal de 1988, na medida em que estabelece dois princípios básicos para a política de atendimento à infância e à adolescência: a descentralização políticoadministrativa e a participação da população por meio de suas organizações representativas. Para Sposati (1999) "a atenção à criança e ao adolescente a partir do Estatuto da Criança e do Adolescente passa a exigir uma nova forma de gestão que construa a proteção integral e o direito geracional da criança e do adolescente" (ibid., p. 93).

Dessa maneira, o Estatuto apresenta uma nova relação do trabalho social entre União, Estados e Municípios, estes últimos passando a ter maior autonomia para implementar e executar suas políticas. Assim, cabem "a coordenação e as normas gerais à esfera federal, a coordenação e a execução às esferas estadual e municipal, bem como às entidades beneficentes e de assistência social" (BRASIL, 1988).

No que se refere à participação da população na formulação e fiscalização das políticas sociais, tanto a Constituição quanto o Estatuto abrem espaço para a criação dos conselhos gestores de políticas públicas, o que, no caso da criança e do adolescente, corresponde aos Conselhos de Direitos da Criança e do Adolescente.

Agora, pela Constituição e o Estatuto, a cidadania organizada está convocada a participar em instâncias até aqui privativas dos homens públicos, dos dirigentes de políticas, dos chamados homens de Estado, como a formulação das políticas e o controle das ações em todos os níveis (COSTA, 1993, p. 41).

Dessa forma, mais uma vez podemos destacar o marco regulatório no Brasil no que tange aos direitos da infância/adolescência em que o ECA representa uma inovação no campo da proteção infanto-juvenil. Em sintonia com o marco regulatório internacional, o ECA, e os esforços que vêm sendo empreendidos por sua regulação, expressos no Sistema Nacional de Atendimento Socioeducativo - SINASE e no Plano 
Nacional de Convivência Familiar e Comunitária - PNCFC, constituem um significativo passo na proposição dos diversos planos e programas em várias frentes de direitos ameaçados ou violados, tais como: trabalho infantil, exploração sexual, violência doméstica, entre outros. Mas não sem contradição, porque os tempos difíceis em que vivemos são de profundo ataque aos direitos no país.

Entendemos que o capital apenas pode se reproduzir produzindo um crescente aumento de destruição, e essa destruição traz rebatimentos para a consolidação do que está expresso no Estatuto da Criança e do Adolescente, sobretudo no que se refere à garantia dos direitos da criança e do adolescente da classe trabalhadora.

Estes ataques têm se dado especialmente no campo das políticas sociais entendidas aqui na sua relação com as expressões da questão social ${ }^{2}$, com as questões estruturais da economia e seus efeitos para as condições de produção e reprodução da vida da classe trabalhadora e na sua relação com as posições tomadas pelas forças políticas em confronto, desde o papel do Estado até a atuação dos grupos que constituem as classes sociais (BEHRING; BOSCHETTI, 2007).

Identifica-se a partir desta consideração que a plena garantia dos direitos apresentados no Estatuto da Criança e do Adolescente tem a sua inviabilidade conferida e confirmada pelo próprio logos da acumulação, que vem perdendo seu fôlego e a capacidade de fazer e de manter concessões a longo prazo. Um dos grandes problemas da política social hoje é a política econômica, cada vez mais perversa, intrinsecamente redutora da igualdade social e cada vez mais concentradora de renda. É só observarmos as políticas sociais de atenção à criança e ao adolescente que temos hoje - focalizadas, seletivas e com recursos financeiros e humanos insuficientes.

Observamos ainda, no campo da política social voltada para o atendimento de crianças e adolescentes, uma clara continuidade histórica de ações voltadas apenas para os segmentos mais pobres da população. Se, antes do Estatuto, isso representava uma preocupação em controlar e disciplinar os pobres, na tentativa de adaptá-los à ordem 
capitalista vigente, hoje também temos a própria diretriz neoliberal defendendo a focalização nas intervenções a serem realizadas no campo social. Assim, qualquer análise sobre esse assunto precisa considerar duas concepções antagônicas e que direcionam formas de intervenções também diferenciadas de enfrentamento das expressões da questão social no que concerne à criança e ao adolescente. De um lado, temos o que preconiza o Estatuto da Criança e Adolescente, que inaugura a Doutrina da Proteção Integral em substituição à Doutrina da Situação Irregular, conforme já apresentamos neste estudo e, de outro, temos o neoliberalismo, que prevê cortes nos gastos sociais e a diminuição do déficit público. Configura-se, no âmbito da formulação da política de atendimento, o embate entre, de um lado, uma proposta amplamente inovadora (o ECA) no que tange à defesa dos direitos das crianças e adolescentes, colocando-os como sujeitos de direitos e dando-lhes prioridade absoluta, além de estabelecer um sistema articulado de ações (Sistema de Garantias), e, de outro lado, propostas neoliberais de focalização, ou seja, intervenções voltadas apenas para o atendimento daqueles que vivem na pobreza extrema.

Logo, a discussão sobre a proteção social pressupõe a discussão da luta de classes, do movimento do capital em relação aos movimentos dos trabalhadores e oprimidos. Esse debate exige reflexões estruturais, uma visão mais abrangente do Brasil e seu futuro, em todos os campos: político, econômico, cultural, ambiental, social. Esse debate exige refletir sobre o papel do Estado e refletir sobre a relação Estado/sociedade civil no momento atual.

Para Anderson (1995, p. 9), o neoliberalismo é uma doutrina que ataca ferozmente "qualquer limitação dos mecanismos de mercado por parte do Estado, denunciando-a como uma ameaça letal à liberdade, não somente econômica, mas também política". As políticas neoliberais foram e são fundamentalmente políticas que agudizam ainda mais as desigualdades sociais já existentes. O neoliberalismo pode ser entendido, em grande parte, como uma atualização histórica do velho liberalismo, que visa decompor e deslegitimar as formas institucionais do movimento operário em luta para restaurar o projeto hegemônico do capital (BRAGA, 1996). O velho liberalismo era anterior a várias conquistas populares de direitos, enquanto que o neoliberalismo busca dar fim a esses direitos conquistados.

No que se refere à proteção social, "os neoliberais sustentam que ela pertence ao âmbito privado. [...] O Estado só deve intervir com o intuito de garantir o mínimo Serv. Soc.\& Saúde, Campinas, SP v. 11, n. 2 (14) p. 167-184 jul./ dez. 2012 ISSN 1676-6806 
necessário para aliviar a pobreza e produzir serviços que os privados não podem ou não querem produzir" (LAURELL, 1995, p. 163). Nesse contexto, todas as políticas sociais devem ser submetidas a cortes, reduções e limitações, para que se realize a contenção do déficit público, meta principal das ações neoliberais. Dessa forma, as políticas sociais brasileiras, que historicamente não haviam apresentado o caráter de extensão dos direitos sociais e políticos e a universalização dos serviços públicos sociais, sofrem um novo ataque em sua forma e conteúdo.

A retração dos gastos estatais com a proteção social também aponta para a focalização das políticas sociais, cada vez mais direcionadas exclusivamente aos mais pobres. Os defensores do neoliberalismo argumentam que o Estado não pode se responsabilizar por todas as pessoas, pois é necessário poupar recursos para desenvolver programas para as pessoas em situação de pobreza absoluta. Deve-se ressaltar, porém, que a focalização perde de vista a perspectiva de cidadania e de direitos sociais, quando prevê o atendimento a apenas uma parcela da população, restando às demais obterem seu atendimento por meio do mercado, o que reforça, assim, o caráter meramente assistencialista do Estado.

Isso fragiliza a efetivação da Doutrina de Proteção Integral, que deve envolver todas as políticas setoriais (saúde, assistência social, educação, esporte, cultura, lazer, etc.), acabando por reforçar a continuidade de duas categorias distintas: o "menor" e a criança: "menor" aqui designando toda a infância pobre, e opondo-se ao conceito de "criança", definida como aquela que vive numa família burguesa. Essa segmentação contribui para que não se consiga formular uma política de direitos universais para crianças e adolescentes.

É nesse contexto que o debate da proteção integral precisa se referir, sobretudo às crianças e adolescentes filhos da classe trabalhadora que tem sofrido o impacto de todas as questões apontadas anteriormente. Pois, ainda que a Lei nos diga que os artigos contidos no ECA são para todos, independente da classe social, sabe-se que numa sociedade dividida em classes e fundada na exploração de uma classe sob a outra, estas acessam os direitos sociais, políticos e civis de forma bastante diferenciada.

Assim, a infância/adolescência ainda guarda no Brasil de hoje as marcas da negação e da violação de direitos conquistados tardiamente e ainda não experimentados de forma plena. Estamos falando de um segmento envolto em atos de exploração e abuso sexual; trabalho infantil; extermínio; medicalização de adolescentes em conflito Serv. Soc. \& Saúde, Campinas, SP v. 11, n. 2 (14) p. 167-184 jan./jun. 2012 ISSN 1676-6806 
com a lei; precárias condições físicas, arbitrariedades e violência nos sistemas socioeducativos; castigos físicos; tratamento humilhante; tendendo inclusive a reiterar enfoques e abordagens que colocam, especialmente o segmento infanto-juvenil das classes populares, como problema, o que mais uma vez impõe limites à efetivação do ECA e da Doutrina da Proteção Integral.

Nesse cenário não é de se espantar que os temas que mais ganharam espaço na agenda pública brasileira nos últimos tempos foram toque de recolher, unidades de internação, situações de exploração e abuso sexual, redução da maioridade penal, violência nas escolas, envolvimento com o tráfico e drogadição. Nota-se em todas as questões apontadas um recorte de classe/raça/etnia/gênero tanto no modo como tem se formado a opinião hegemônica, quanto na execução das políticas sociais que podem responder de formas diferentes, ou enfrentando ou minimizando os efeitos deste processo desumanizador. No entanto, é necessário para este enfrentamento, que se solidifique uma política que promova a universalização dos direitos e fortaleça o Sistema de Garantias, com incisiva ação de defesa, proteção e responsabilização.

\section{CONSIDERAÇÕES FINAIS}

Todo o caminho percorrido nos permite considerar que apesar das conquistas duramente garantidas e do esforço nos últimos 20 anos do novo marco regulatório, o processo de consolidação no plano das normativas e das ações está incompleto, ainda revelando uma rede de proteção fragilizada pela fragmentação, desarticulação, não estruturação, além das práticas que contrastam com o ideário dos direitos e retomam formas conhecidas de filantropia, repressão e criminalização.

Faz-se importante recuperar que a política social, no capitalismo maduro, não é capaz de reverter o quadro de acirramento das expressões da questão social que atingem em especial as crianças e adolescentes da classe trabalhadora, nem é essa a sua função estrutural.

Neste campo muitas vezes temos visto a responsabilização pelo cuidado e formação infanto-juvenil atribuída à família que significa, em última análise, culpabilizá-la quando há na realidade um complexo sistema estruturado em relações fundadas na exploração e opressão. Por isso insistirmos na ideia de que as instituições governamentais, assim como as não governamentais, componentes da rede de proteção, 
devem politizar o atendimento à criança e ao adolescente, visto que ele expressa relações sócio-políticas e econômicas de dominação-emancipação.

Neste caminho, cabe aos profissionais, militantes, sujeitos políticos coletivos, intelectuais e defensores de uma nova ordem societária levar as políticas sociais ao limite da sua cobertura numa agenda de luta dos trabalhadores em defesa da emancipação humana, tendo como horizonte elevar o padrão de vida das maiorias e promover mudanças mais profundas e radicais. Nesse sentido, debater e lutar pela ampliação e efetivação dos direitos sociais previstos no Estatuto da Criança e do Adolescente, pressupõe a discussão coletiva, a disputa pelo fundo público, a socialização da política e a organização dos sujeitos políticos.

Entendemos que a ampliação do Estado será mais ou menos possível conforme o movimento histórico da luta de classes, e conforme venha a se estabelecer a correlação de forças. Assim, a política de atendimento preconizada pelo Estatuto da Criança e do Adolescente oscila entre o direito formal e a violação cotidiana desses direitos, visto que nesta sociedade de classes as leis também expressam as contradições do capitalismo, por isso devemos enfrentar diariamente as batalhas para radicalizar a cidadania da população infanto-juvenil que por muitas vezes teve a sua voz calada pelo descaso e pela violência. Faz-se mais do que necessário, criar outras mediações que busquem novas formas de organização da vida.

\section{REFERÊNCIAS}

ADORNO, S. A gestão filantrópica da pobreza urbana. São Paulo em perspectiva. São Paulo, v. 4, n. 2, p. 9-17, 1990.

ANDERSON, P. Balanço do neoliberalismo. In: SADER, E. et al. Pós-neoliberalismo: as políticas sociais e o Estado democrático. Rio de Janeiro: Paz e Terra, 1995.

BEHRING. E. R.; BOSCHETTI, I. Política Social: fundamentos e história. 2. ed. São Paulo: Cortez, 2007.

BRAGA, R. A restauração do capital: um estudo sobre a crise contemporânea. São Paulo: Xamã, 1996.

BRASIL. Constituição (1988). Constituição [da] República Federativa do Brasil. Brasília: Senado Federal, 1988.

COSTA, A. C. É possível mudar. São Paulo: Cortez, 1993.

Serv. Soc. \& Saúde, Campinas, SP v. 11, n. 2 (14) p. 167-184 jan./jun. 2012 ISSN 1676-6806 
CUNHA, E. P.; CUNHA, E. S. M. Políticas Públicas Sociais. In: CARVALHO, A. (Org.). Políticas Públicas. Belo Horizonte: UFMG, PROEX, 2002.

DOIMO, A. M. Movimentos sociais e participação política: a problemática contemporânea da ação-direta. In: CAMINO, L.; LHULLIER, L.; SANDOVAL, S. Estudos sobre comportamento político: teoria e pesquisa. Florianópolis: Letras Contemporâneas, 1997.

IAMAMOTO, M. V. O Serviço Social na contemporaneidade: trabalho e formação profissional. 3. ed. São Paulo: Cortez, 2000.

LAURELL, A. C. Avançando em direção ao passado: a política social do neoliberalismo. In: LAURELL, A. C. (Org.). Estado e políticas sociais no neoliberalismo. 2. ed. São Paulo: Cortez, 1997.

RIZZINI, I; PILOTTI, F. A arte de governar crianças: a história das políticas sociais, da legislação e da assistência à infância no Brasil. Rio de Janeiro: Editora Universitária Santa Úrsula, 1995.

RIZZINI, I. O século perdido: raízes históricas das políticas públicas para a infância no Brasil. Rio de Janeiro: Santa Úrsula, 1997.

SPOSATI, A. Políticas sociais nos governos petistas. In: MAGALHÃES, I. et al. (Orgs.). Governo e cidadania: Balanço e reflexões sobre o modo petista de governar. São Paulo: Fundação Perseu Abramo, 1999. 
Serv. Soc. \& Saúde, Campinas, SP v. 11, n. 2 (14) p. 167-184 jan./jun. 2012 ISSN 1676-6806 